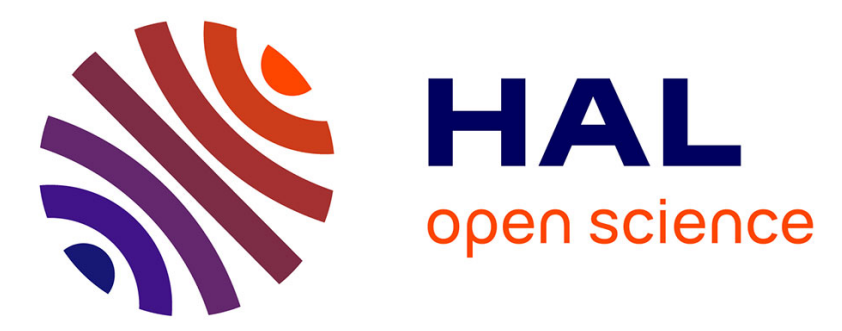

\title{
Electrochemical study of conductive nanometric Co3O4-based electrodes for asymmetric supercapacitors in alkaline electrolyte
}

Gérôme Godillot, Pierre-Louis Taberna, Barbara Daffos, Patrice Simon, Claude Delmas, Liliane Guerlou-Demourgues

\section{To cite this version:}

Gérôme Godillot, Pierre-Louis Taberna, Barbara Daffos, Patrice Simon, Claude Delmas, et al.. Electrochemical study of conductive nanometric Co3O4-based electrodes for asymmetric supercapacitors in alkaline electrolyte. Journal of The Electrochemical Society, 2016, 163 (9), pp.A2004-A2010. 10.1149/2.0951609jes . hal-01358733

\section{HAL Id: hal-01358733 https://hal.science/hal-01358733}

Submitted on 19 Jan 2021

HAL is a multi-disciplinary open access archive for the deposit and dissemination of scientific research documents, whether they are published or not. The documents may come from teaching and research institutions in France or abroad, or from public or private research centers.
L'archive ouverte pluridisciplinaire HAL, est destinée au dépôt et à la diffusion de documents scientifiques de niveau recherche, publiés ou non, émanant des établissements d'enseignement et de recherche français ou étrangers, des laboratoires publics ou privés. 


\title{
Electrochemical Study of Conductive Nanometric $\mathrm{Co}_{3} \mathrm{O}_{4}$ - Based Electrodes for Asymmetric Supercapacitors in Alkaline Electrolyte
}

\author{
G. Godillot, ${ }^{\text {a }}$ P.-L. Taberna, ${ }^{\mathrm{b}, \mathrm{c}}$ B. Daffos, ${ }^{\mathrm{b}, \mathrm{c}}$ P. Simon, ${ }^{\mathrm{b}, \mathrm{c}}$ C. Delmas, ${ }^{\mathrm{a}}$ \\ and L. Guerlou-Demourgues ${ }^{a, c, z}$ \\ ${ }^{a}$ CNRS, Univ. Bordeaux, Bordeaux INP, ICMCB UPR 9048, F-33600 Pessac, France \\ ${ }^{b}$ CIRIMAT UMR 5085, Université de Toulouse, F-31062 Toulouse, France \\ ${ }^{c} R S 2 E$, Réseau Français sur le Stockage Electrochimique de l'Energie, FR CNRS 3459, France
}

\begin{abstract}
Lithiated and protonated spinel cobalt oxide, exhibiting high electrical conductivity thanks to the presence of structural defects, could be envisioned for asymmetric supercapacitor applications. Charge storage mechanism was investigated and it is shown that only a thin layer at the material surface was involved (less than $1 \mathrm{~nm}$ ) during the process, so that only $20 \%$ of the total theoretical capacity was achieved. A very good electrochemical stability is found, with less than $30 \%$ of the initial capacity $\left(\sim 70 \mathrm{~mA} \cdot \mathrm{h} \cdot \mathrm{g}{ }^{-1}\right)$ lost after 3500 cycles.
\end{abstract}

An increasing number of studies is devoted to the field of supercapacitors since they are now used or envisaged to be used in a large range of applications for reversible energy storage such as in the fields of space, aircrafts, transportation (hybrid vehicles) and smart grids. An important research line, aiming at increasing both energy and power densities, is devoted to asymmetric transition metal oxides/activated carbon (C) systems. Among them, $\mathrm{RuO}_{2}$-based devices are the most interesting in terms of capacitance (more than $700 \mathrm{~F} / \mathrm{g})^{1}$ but their application is limited to the domain of small electronic devices because of high cost. Cheaper oxides such as cobalt, ${ }^{2}$ manganese, ${ }^{3-5}$ vanadium, ${ }^{6}$ nickel $^{7}$ or iron $^{8}$ oxides, as well as conducting polymers ${ }^{9}$ such as polyaniline, polypyrole or PEDOT, have been extensively studied as supercapacitor electrode materials. The $\mathrm{MnO}_{2} /$ carbon system is the most investigated system (more than 600 papers in the last 3 years) ${ }^{10}$ due to its capability to work in aqueous medium at potentials up to $2 \mathrm{~V}$, as well as to the low cost and environmental friendliness of manganese. Nevertheless, this system suffers from the poor electronic conductivity of manganese oxides and the limited ion diffusion/transport through the electrode, which limits the performances especially in terms of power. This problem is usually addressed by simply mixing carbon materials (carbon black, CNTs) with $\mathrm{MnO}_{2}$ or by developing elaborated grafting or decoration strategies. ${ }^{11-14}$

Our approach distinguishes itself from many works by the design of cobalt oxides exhibiting high electronic conductivity thanks to the presence of tetravalent cobalt ions. In this context, highly conductive nanometric spinel type cobalt oxides, with original composition, were prepared in the laboratory. ${ }^{15-17}$ These oxides, which can be successfully used as conductive additives for the positive electrode of Ni-MH batteries, are synthesized by oxidizing precipitation of cobalt nitrate in a basic medium at $90^{\circ} \mathrm{C}$. ${ }^{15}$ These phases can be distinguished from ideal $\mathrm{Co}_{3} \mathrm{O}_{4}$, by the presence of protons, lithium and cobalt vacancies within the structure, as well as of $\mathrm{Co}^{4+}$ in the octahedral trivalent cobalt network, leading to formulae such as:

$$
\begin{aligned}
& \mathrm{H}_{1.34} \mathrm{Li}_{0.14} \mathrm{Co}_{0.61}^{\mathrm{II}} \quad\left[\mathrm{Co}^{\mathrm{III}}{ }_{1.58} \mathrm{Co}^{\mathrm{IV}}{ }_{0.14}\right] \mathrm{O}_{4} \bullet 0.32 \mathrm{H}_{2} \mathrm{O} \\
& \text { Tetrahedral sites }
\end{aligned}
$$

The $\mathrm{Co}^{\mathrm{III}} / \mathrm{Co}^{\mathrm{IV}}$ mixed valency within the 3 dimensional octahedral network (edge-sharing $\mathrm{CoO}_{6}$ octahedra) entails electronic delocalization through the recovering of the $t_{2 g}$ orbitals and very good electronic conductivity properties. The conductivity values reach about $5 \times 10^{-4}$ $\mathrm{S} / \mathrm{cm}$ at room temperature, which corresponds to an increase of conductivity by 2 decades versus ideal $\mathrm{Co}_{3} \mathrm{O}_{4}$, in which no electronic delocalization can be achieved because of the full $\mathrm{t}_{2 \mathrm{~g}}$ orbitals of the only $\mathrm{Co}^{\mathrm{III}}$ ions present in the octahedral network. Controlled thermal treatment of our materials induces a departure of protons from the structure, coupled with a cationic redistribution within the spinel

${ }^{\text {zE} E-m a i l: ~ l i l i a n e . g u e r l o u-d e m o u r g u e s @ i c m c b . c n r s . f r ~}$ framework, an increase of the $\mathrm{Co}^{4+}$ amount in the octahedral network and therefore an increase of the electronic conductivity. ${ }^{16,17}$ Materials heated in the $150-300^{\circ} \mathrm{C}$ range exhibit the highest conductivities, around $10^{-1} \mathrm{~S} / \mathrm{cm}$, which corresponds to 3 decades higher than for the pristine spinel material. Aside, quite high specific areas $\left(180 \mathrm{~m}^{2} / \mathrm{g}\right.$ for the material heated at $200^{\circ} \mathrm{C}$ ) could be obtained. These conductivity and surface features make them good candidates for supercapacitor electrodes.

The present work aims, in a first step, at determining the effect of temperature annealing on the electrochemical behavior by studying the following three materials: pristine nanometric spinel phase (denoted as SP-initial in the following) and the phases resulting from its heating at $200^{\circ} \mathrm{C}$ and $300^{\circ} \mathrm{C}$ (denoted as SP-200 and SP-300 respectively). The stability of the electrodes upon cycling will then be investigated, and the electrochemical process as well as the charge storage mechanism will be addressed.

\section{Experimental}

Material preparation.-As detailed elsewhere, ${ }^{15}$ powder of pristine nanometric $\mathrm{Co}_{3} \mathrm{O}_{4}$ phase was prepared by precipitation at $90^{\circ} \mathrm{C}$ of a cobalt salt in a $8 \mathrm{M}-\mathrm{KOH}+0.5 \mathrm{M}-\mathrm{NaOH}+0.5 \mathrm{M}-\mathrm{LiOH}$ alkaline solution. Cobalt nitrate hexahydrate (Fluka) was dissolved into distilled water, mixed with hydrogen peroxide (Fluka) (with a $\mathrm{Co}\left(\mathrm{NO}_{3}\right)_{2}: \mathrm{H}_{2} \mathrm{O}_{2}$ molar ratio of 3:2), and then added drop-wise to the ternary alkaline solution to induce precipitation of the nanometric cobalt oxide. The solution obtained was ripened for 4 hours, washed with distilled water until neutrality, and then dried at $60^{\circ} \mathrm{C}$ for $24 \mathrm{~h}$. The resulting powder was finally ground with a pestle and mortar.

The initial nano- $\mathrm{Co}_{3} \mathrm{O}_{4}$ powder was subjected to heat treatments, under air, at 200 and $300^{\circ} \mathrm{C}$. The temperature was increased at the rate of $2^{\circ} \mathrm{C} / \mathrm{min}$ up to the target temperature, held for a 4 hours- isothermal stage, and then decreased down to room temperature at $2^{\circ} \mathrm{C} / \mathrm{min}$. The starting fresh precipitated material is denoted in the following as SPinitial (SP for spinel), while the heated samples are denoted as SP-200 and SP-300, depending on the treatment temperature.

Electrode preparation.-A proper amount of cobalt oxide powder, $5 \%$ in mass PTFE (DuPont de Nemours), and 5\% of carbon black (conductive additive made of acetylene, $100 \%$ compressed, Alfa Aesar) were mixed with ethanol. The mixture was set as a freestanding film, in which a $11 \mathrm{~mm}$-diameter disc was cut and then pressed on nickel foam (current collector) at $100 \mathrm{MPa}$. The electrode was finally dried at $60^{\circ} \mathrm{C}$ for $12 \mathrm{~h}$. The mass loading of the discs is about 20 to $30 \mathrm{mg} \cdot \mathrm{cm}^{-2}$ and the thickness is about $40-60 \mu \mathrm{m}$.

The optimization of the carbon black amount within the electrode has been reported in a previous paper. ${ }^{18}$ As presented in Supplementary Figure 1, among the electrodes containing from 0 up to $20 \%$ of carbon additive, the addition of only $5 \%$ of carbon black enables to 
increase the initial capacity by more than $70 \%$ and the best discharge capacity is obtained for $15 \%$ of carbon black. However, if the capacity is normalized to the total active material weight (cobalt oxide+carbon black) and not only to the mass of cobalt oxide, the compositions between 5 and $15 \%$ give almost the same results in terms of specific capacity. We decided therefore to use only $5 \%$ carbon added, in order to limit the composite effects during the study of our cobalt oxides, all the more as these materials exhibit quite good conductivity values.

Electrochemical characterization.-Electrochemical performances were evaluated in a three-electrode cell (classical corrosion cell from Radiometer Analytical, France), filled with a $5 \mathrm{M}-\mathrm{KOH}$ electrolyte. The preparation of the working electrode is detailed just above. Platinum was used as counter electrode and $\mathrm{HgO} / \mathrm{Hg}$ in $1 \mathrm{M}$ $\mathrm{KOH}$ as reference electrode. Cyclic voltammetry was achieved using a VMP3 potentiostat (Biologic) between $-0.4 \mathrm{~V}$ and $0.75 \mathrm{~V}$ vs. SHE.

An additional kinetic study was also carried out using a $35 \mu \mathrm{m}$ cavity microelectrode in order to get rid of the ohmic drop. Actually, few $\mu \mathrm{g}$ or so are packed into the cavity leading to current in the $\mu \mathrm{A}$ range enabling sweep rates as high as several $\mathrm{V} \mathrm{s}^{-1}$ in cyclic voltammetry. Such an electrode stands as the working electrode, with a platinum counter electrode and a $\mathrm{HgO} / \mathrm{Hg}$ reference electrode. The main advantage of this system lays in the small amount of material used (several $\mathrm{ng}$ to $\mathrm{mg}$ of powder in the cavity), which allows to limit current and therefore ohmic drop, the sensitivity to cell geometry being moreover weakened. The redox peaks obtained are indeed better defined than with a macroscopic electrode, which is suitable to discriminate electrochemical phenomena that would be superimposed with a macroelectrode. Unfortunately, the very small amount of materials prevents from doing any quantitative analysis, as determining valuable capacity values.

Cycled electrodes were analyzed by XRD and SEM. For this purpose, six electrodes were primarily prepared, and activated by performing 10 oxidation-reduction cycles between $-0.4 \mathrm{~V}$ and $0.75 \mathrm{~V}$ in $5 \mathrm{M}-\mathrm{KOH}$. The potential of each electrode was then maintained during 12 hours at the target value, $-0.20,0.10,0.30,0.47,0.60$ and $0.70 \mathrm{~V}$ respectively. After rinsing the electrode out with deionized water, each electrode was dried at $60^{\circ} \mathrm{C}$, and finally analyzed by XRD and SEM. $\mathrm{X}$-ray diffraction (XRD) data of the cycled electrodes were collected with a Philips PANalytical X'Pert Pro diffractometer using the cobalt $\mathrm{K} \alpha$ radiation. The diffraction patterns were recorded for around 11 hours (800.1 s per step) in the $10-110^{\circ}(2 \theta)$ angular range, with a $0.0167^{\circ}(2 \theta)$ step size and a $2.122^{\circ}(2 \theta)$ active width in the detector. Scanning electron micrographs were collected with a Hitachi S-4500 field emission microscope with an accelerating voltage of $3.0 \mathrm{kV}$ in secondary electrons mode.

\section{Results and Discussion}

Study of the potential window.-Fig. 1 presents the voltammograms obtained for different cutoff voltages of the spinel (SP-initial) based electrode, registered in $5 \mathrm{M}-\mathrm{KOH}$. The choice of potential window appears crucial for this system because, the best compromise must be found between the desired oxidation of the positive electrode material, to reach the highest capacity, and the unwanted electrolyte oxidation, to maintain a high coulombic efficiency. As shown in Fig. 1-insert, the charge integration of the cathodic branches of voltammograms, registered between a minimum potential of $-0.2 \mathrm{~V}$ and a maximum potential $\left(\mathrm{E}_{\max }\right)$ of $0.80 \mathrm{~V}$, leads to a constant increase of the cathodic capacity vs $\mathrm{E}_{\max }$ value. Nevertheless, the coulombic efficiency, which is kept above $90 \%$ for $\mathrm{E}_{\max }<0.70 \mathrm{~V}$, strongly decreases for higher potential values, due to the oxidation of water electrolyte. On the basis of the coulombic efficiency measured, the maximum electrode potential will then be fixed at $0.75 \mathrm{~V}$ vs SHE, which ensures a coulombic efficiency of at least $90 \%$ (sufficient for an open cell). It must be noticed that, from the thermodynamic viewpoint the OER in $5 \mathrm{M}-\mathrm{KOH}$ is supposed to occur at $0.35 \mathrm{~V}$ vs SHE. However, resulting from the strong over potential of the oxygen release reaction on the
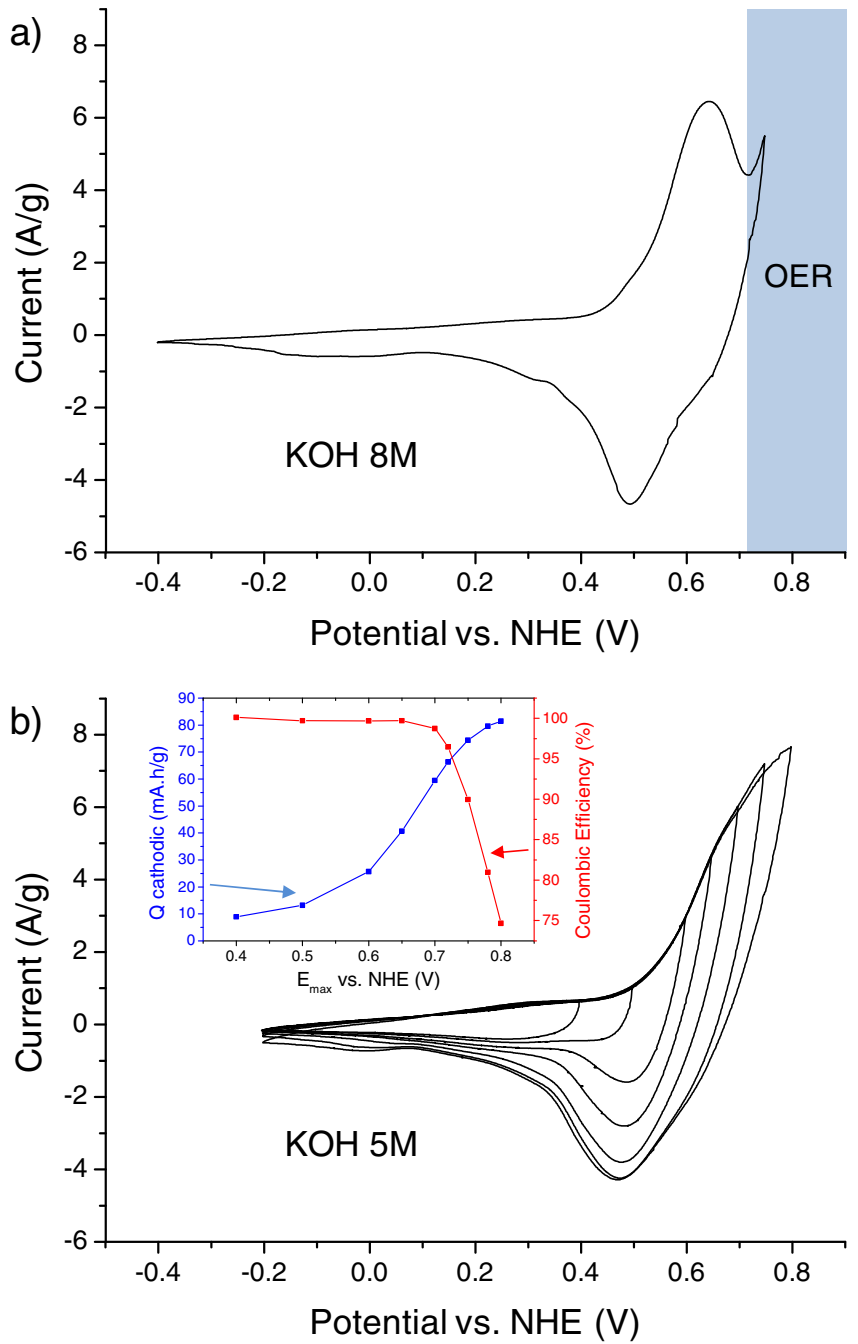

Figure 1. Cyclic voltammetry curves, at $5 \mathrm{mV} / \mathrm{s}$, of a SP-initial based electrode containing $5 \%$ additional carbon black, (a) registered in $8 \mathrm{M}-\mathrm{KOH}$ in the $-0.4-0.75 \mathrm{~V}$ range, (b) registered in $5 \mathrm{M}-\mathrm{KOH}$ in the $-0.2-0.4 / \ldots / 0.80 \mathrm{~V}$ range. As an insert of Fig. 1b, the variations of cathodic capacity and of coulombic efficiency are plotted as a function of maximum potential $\left(\mathrm{E}_{\max }\right)$.

nanometric $\mathrm{Co}_{3} \mathrm{O}_{4}$ type materials, ${ }^{19,20}$ this reaction is set off only at higher potential $(0.75 \mathrm{~V})$.

Comparative cyclic voltammetry study of the materials synthesized at various temperatures (SP-initial, SP-200 and SP-300).As stated in the introduction section and reported in previous publications, ${ }^{8,9}$ a thermal treatment of a nanometric $\mathrm{Co}_{3} \mathrm{O}_{4}$ type phase (SP-initial) leads to an increase of the electronic conductivity from $3.10^{-4} \mathrm{~S} . \mathrm{cm}^{-1}$ to $9.1 .10^{-2} \mathrm{~S} . \mathrm{cm}^{-1}$, for annealing temperatures higher than $150^{\circ} \mathrm{C}$. In the same time, the specific area of the powders tends to drop beyond $300^{\circ} \mathrm{C}\left(200 \mathrm{~m}^{2} / \mathrm{g}\right.$ for SP-initial, $180 \mathrm{~m}^{2} / \mathrm{g}$ after annealing at $200^{\circ} \mathrm{C}$ and $98 \mathrm{~m}^{2} / \mathrm{g}$ after annealing at $300^{\circ} \mathrm{C}$ ), as shown in Supplementary Fig. 2. The materials, thermally treated between 150 and $300^{\circ} \mathrm{C}$, are therefore likely to exhibit interesting electrochemical properties because they present a good compromise between conductivity and surface area.

The voltammograms of electrodes prepared from the materials treated at $200^{\circ} \mathrm{C}$ and $300^{\circ} \mathrm{C}$ (SP-200 and SP-300) were then investigated in $5 \mathrm{M}-\mathrm{KOH}$ at $5 \mathrm{mV} / \mathrm{s}$, and compared to the pristine material. They are presented in Fig. 2. In the case of the two thermally treated materials, a capacitive envelope is observed at low potential (from $-0.4 \mathrm{~V}$ vs. NHE to $0.1 \mathrm{~V}$ vs. NHE), which tends to widen with the synthesis temperature. This behavior may be explained by an electrostatic 


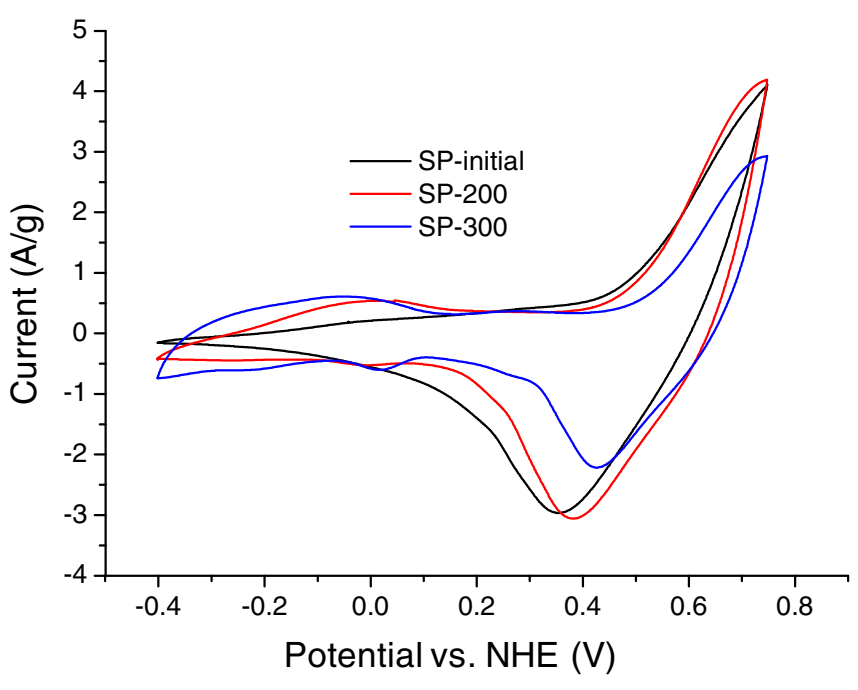

Figure 2. Cyclic voltammetry measurements at $5 \mathrm{mV} / \mathrm{s}$ in $5 \mathrm{M}-\mathrm{KOH}$ of 3 electrodes prepared with SP-initial, SP-200 and SP-300 active material, with $5 \%$ carbon black added.

charge storage, resulting from the higher electronic conductivity of the heated phases. An additional peak around $0 \mathrm{~V}$ in reduction can also be observed the thermally treated materials, and was assigned to the presence of carbon black. As shown in Supplementary Fig. 3, the voltammogram of an electrode that was prepared with carbon black only, exhibits indeed a cathodic peak between -0.2 and $0 \mathrm{~V}$, probably due to metal traces involved in the synthesis. The fact that no additional peak around $0 \mathrm{~V}$ can be observed for the SP-initial sample may result from the lower conductivity of this sample as compared with the others. ${ }^{17}$ No significant change in the oxidation and reduction peaks of cobalt oxides has to be noticed for SP-initial and SP-200, but the current drops for SP-300, which is assumed to result from the lower specific surface area of this material $\left(98 \mathrm{~m}^{2} / \mathrm{g}\right.$ against $200 \mathrm{~m}^{2} / \mathrm{g}$ for SP-initial).

The capacity of the three materials were determined by integrating the cathodic branches of the voltammograms of Fig. 2, and are shown in Table I. The overall trend shows a decrease of the gravimetric capacity when temperature increases. Differently from what was expected on the basis of the increase of electronic conductivity, no significant increase of the specific capacity is observed after thermal treatment at $200^{\circ} \mathrm{C}$ of SP-initial. The improvement of the electronic properties with temperature either does not seem to induce any increase of the electrochemical active surface, or in a so weak extent that the capacity increase is counter balanced by the slight decrease of the specific surface area of the heated material $\left(180 \mathrm{~m}^{2} / \mathrm{g}\right.$ for SP-200 versus $200 \mathrm{~m}^{2} / \mathrm{g}$ for SP-initial). For the SP-300 sample, the specific surface area is half the pristine one, severely limiting the faradaic storage capability, leading to a total capacity lower than those of the other two materials. The capacity change with the annealing temperature of the three materials will be discussed back later.

It seems that the electronic conductivity of the various samples does not influence in the same way the behavior in the area between -0.4 and $0.1 \mathrm{~V}$ vs. NHE, which is governed by double layer process, and in the area between 0.2 and $0.75 \mathrm{~V}$ vs. NHE, which is governed

Table I. Cathodic capacities, extracted from voltammograms of Fig. 2, for the electrodes prepared from the materials SP-initial, SP. 200 and SP-300. The values are reported with the unities $\mathrm{mA} . \mathrm{h} / \mathrm{g}$ and F/g over $1.15 \mathrm{~V}$.

\begin{tabular}{lccc} 
& SP-initial & SP-200 & SP-300 \\
\hline Cathodic capacity (mA.h/g) & 60.1 & 62.3 & 48.7 \\
Cathodic capacitance (F/g) & 188 & 195 & 152
\end{tabular}

by faradaic process. In the former region, the increase of the current with annealing temperature increasing can be attributed to the increase of the electronic conductivity. In the faradaic region, complex phenomena including ionic motion are involved, so that the decrease of the specific area with annealing temperature increasing becomes predominant with regard to electronic conductivity.

It appears that SP-initial and SP-200 offer the best electrochemical performance in terms of specific capacity. Importantly, for SP-initial, the main part of storage occurs between 0.4 and $0.75 \mathrm{~V}$, while a significant part of the storage process occurs at lower potential (between $-0.4 \mathrm{~V}$ and $0.1 \mathrm{~V}$ ) for SP-200, which is not suitable for applying in hybrid C/metal oxide supercapacitors. The SP-initial material appears consequently as the most promising one from the application point of view. Nevertheless, we will also consider the SP-200 material in the subsequent study, because its weak resistance due to its higher conductivity is likely to be interesting in high rate tests.

Influence of scan rate on the electrochemical behavior.-The electrochemical behavior of the SP-initial and SP-200 samples were thus investigated by cyclic voltammetry in $5 \mathrm{M}-\mathrm{KOH}$ in two different configurations: the classical microelectrode, which was used for quantitative analysis in the previous section, and the cavity microelectrode for the study of qualitative phenomena.

Macroelectrode study.-Figure 3 shows the cyclic voltammograms of the SP-initial sample at scan rates ranging from 0.1 to $200 \mathrm{mV} / \mathrm{s}$. The electrochemical signatures of the two electrodes based on SP-initial and SP-200 samples are similar; only the curves corresponding to SP-initial are therefore presented in Fig. 3. When scan rate increases, the faradaic peaks are widened, as a result of high ohmic drop. The resistance of electrolyte $(>1 \Omega)$, together with high current values (several dozen of $\mathrm{mA}$ ), tends to distort the electrochemical signal. The potential difference between the oxidation and reduction peaks increases also with scan rate. As a result, the oxidation peak of cobalt oxide merges with that of electrolyte beyond $2 \mathrm{mV} / \mathrm{s}$, which evidences slower charge transfer kinetics.

The evolution of the cathodic capacities of the SP-initial and SP200 materials as a function of scan rate is shown in Fig. 4. For the highest scan rates $(10<\mathrm{v}<200 \mathrm{mV} / \mathrm{s})$, the capacity exhibits similar evolutions for both materials, with an increase until a maximum value when the scan rate decreases. For scan rates below $5 \mathrm{mV} / \mathrm{s}$, the capacity of the SP-initial sample becomes higher than that of the heated material. At the lowest scan rates, the presence of a leakage current explains that the capacity is lower than theoretical one $\left(\sim 223 \mathrm{~mA} \cdot \mathrm{h} \mathrm{g}^{-1}\right)$.

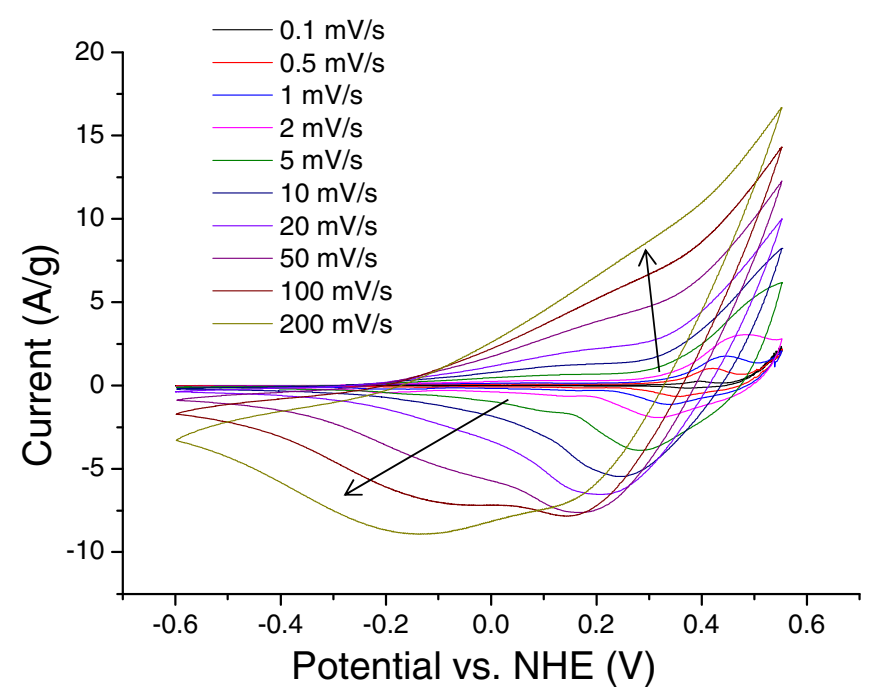

Figure 3. Cyclic voltammetry measurements in $5 \mathrm{M}-\mathrm{KOH}$ of an electrode prepared with SP-initial (with $5 \%$ carbon black added), at scan rates varying from 0.1 to $200 \mathrm{mV} / \mathrm{s}$. 


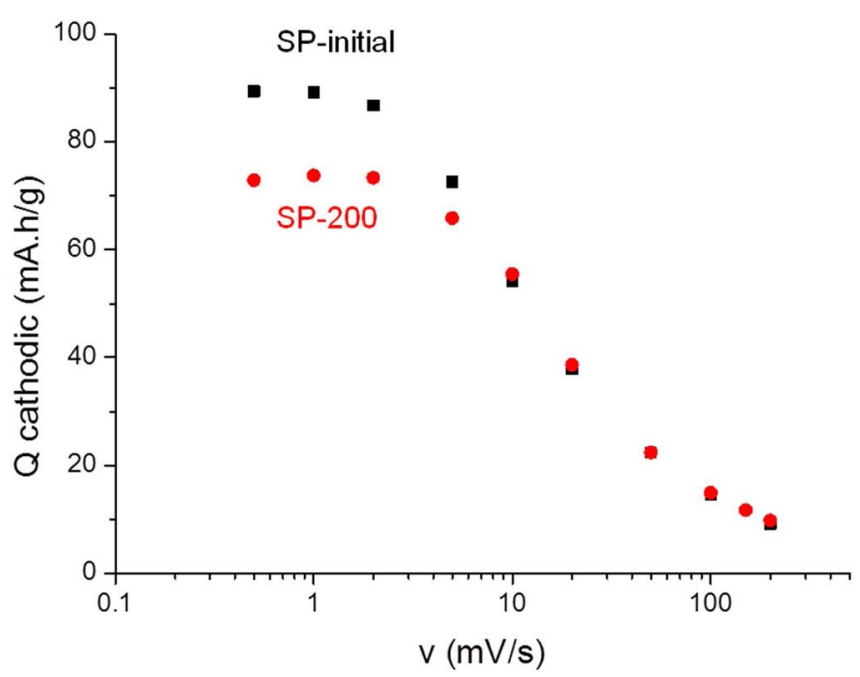

Figure 4. Cathodic capacities extracted from voltammograms registered in $5 \mathrm{M}-\mathrm{KOH}$, at scan rates varying from 0.1 to $200 \mathrm{mV} / \mathrm{s}$, for two electrodes prepared with SP-initial and SP-200 (with 5\% carbon black added). The values obtained for SP-initial correspond to the curves of Fig. 3.

For the SP-200 sample, the higher electronic conductivity can induce a decrease in the observed oxygen evolution overpotential - and then faster electrolyte oxidation - which can explain the smaller capacity obtained at low scan rate. Again, as indicated in the previous section, the electrochemical performances of the electrode based on SP-200 do not appear as better than those of the electrode based on SP-initial, in spite of the higher electronic conductivity of the former material.

Microelectrode study.-To limit the ohmic drop concern in conventional electrochemical cell, the electrochemical behavior of the SP-initial and SP-200 materials were evaluated using a cavity microelectrode (described in the experimental part). The cyclic voltammograms of the two materials are given in Fig. 5. Oxidation-reduction peaks registered at high rate are, as expected, much less distorted than when using a macroelectrode, which supports the hypothesis of a strong contribution of ohmic drop with the macroelectrode. In addition, the microelectrode measurements clearly show the presence of two reduction peaks, around 0.50 and $0.40 \mathrm{~V}$. This will be discussed later.

The difference in the redox potentials $\left(\mathrm{E}_{\mathrm{ox}}-\mathrm{E}_{\mathrm{red} 1}\right)$ and $\left(\mathrm{E}_{\mathrm{ox}}-\mathrm{E}_{\mathrm{red} 2}\right)$ of the SP-initial and SP-200 samples are plotted in Fig. 6, where $\mathrm{E}_{\mathrm{ox}}, \mathrm{E}_{\mathrm{red} 1}$ and $\mathrm{E}_{\mathrm{red} 2}$ correspond to the oxidation peak, the reduction peak at higher potential and the reduction peak at lower potential respectively. It appears clearly that the potential difference is lower for SP-200, which highlights the lower intrinsic resistance of this material and faster reaction kinetics than for SP-initial. This effect could not be observed in macroelectrode configuration, because of the extrinsic additional ohmic drops, associated with electrode thickness or electrolyte resistance.

Structural study of the electrode during cycling.- - In order to investigate the mechanisms involved during the electrochemical cycling, electrodes based on the nanometric SP-initial material were studied by XRD and SEM, after polarization at various constant potentials, as described in the Experimental section and indicated in Supplementary Fig. 4. The XRD diffractograms registered for each potential are similar to that obtained for the pristine material, and show that the $\mathrm{Co}_{3} \mathrm{O}_{4}$ structure is maintained all along the cycling, without any additional phase appearing and without any significant change of the grain size (no variation of the line width, usually characteristic of a modification of the size of the coherent domains). The electrodes were then analyzed by SEM; the pictures obtained for the electrodes prepared at $0.1,0.6$ and $0.7 \mathrm{~V}$ can be compared to those of the starting non cycled
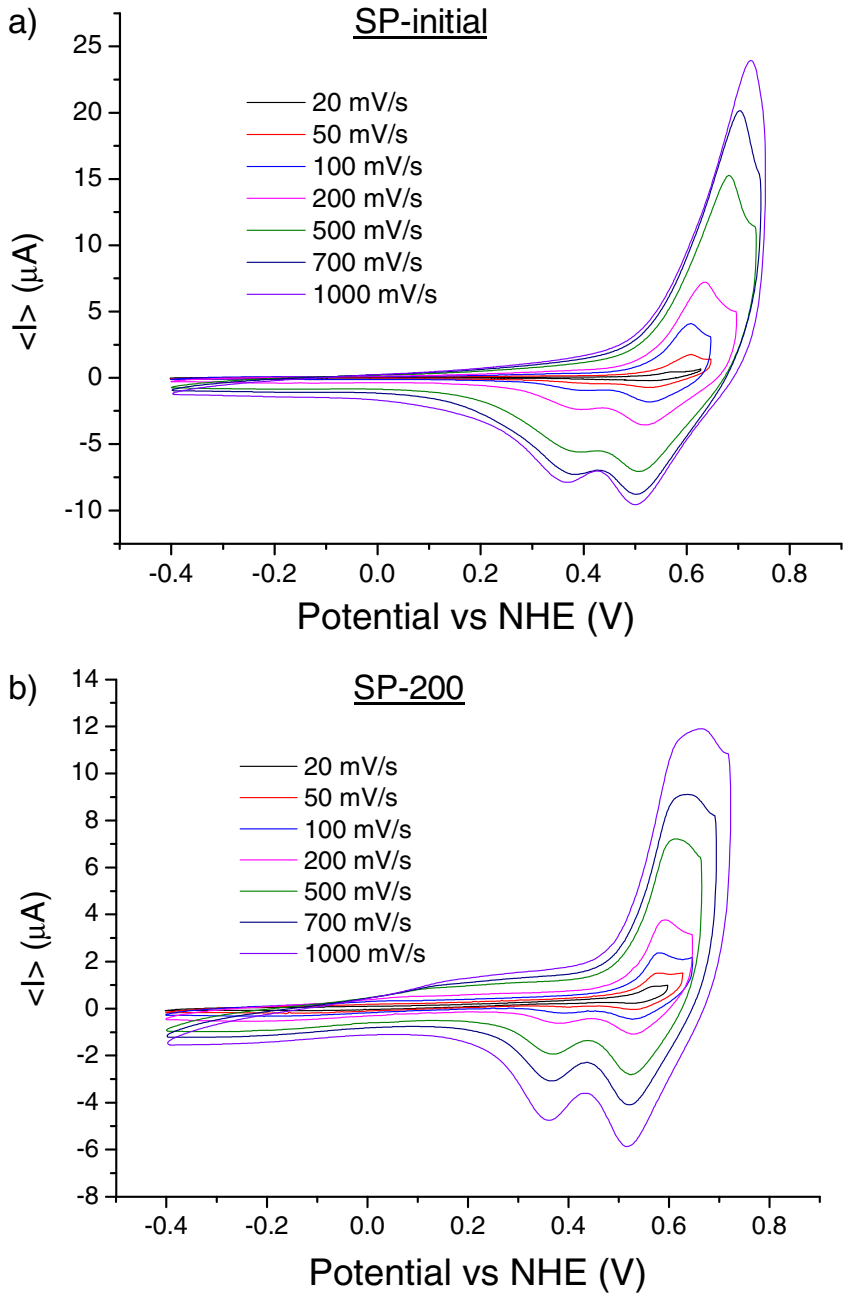

Figure 5. Cyclic voltammetry measurements in microelectrode in $5 \mathrm{M}-\mathrm{KOH}$ for powders of (a) SP-initial and (b) SP-200 (with 20\% carbon black added), at scan rates varying from 20 to $1000 \mathrm{mV} / \mathrm{s}$.

electrode in Fig. 7. Except for the starting electrode, the other three electrodes exhibit, in addition to nanometric grains characteristic of the starting $\mathrm{Co}_{3} \mathrm{O}_{4}$ phase, domains that are recovered by platelets, which are several hundreds of nm large. EDX analysis has shown that these domains are mainly constituted of cobalt element. Such platelet morphology is characteristic of $\mathrm{Co}(\mathrm{OH})_{2}$ or $\mathrm{CoOOH}$ cobalt hydroxides. ${ }^{21-23}$ However, no such phase was detected by XRD in the electrodes prepared at various potentials. However, during these experiments, the electrodes were removed from the electrochemical cell, rinsed with water, and dried, before being investigated by XRD. A chemical modification of the material during this process of electrode preparation cannot be excluded, as, for instance, a spontaneous reduction for the electrodes recovered at high potential. To avoid any misinterpretation, an electrode was also characterized in situ during the electrochemical cycling and the results, not reported here, confirm that only the $\mathrm{Co}_{3} \mathrm{O}_{4}$ type phase is present all along the cyclic voltammogram, with no crystallinity modification. As a consequence, the platelets, observed by SEM, can be reasonably supposed to be particles of $\mathrm{Co}(\mathrm{OH})_{2}$ or $\mathrm{CoOOH}$ agglomerated in thin layers, localized in some domains at the near surface of the electrodes, so that they could not be detected by XRD. The formation mechanism of these cobalt hydroxide type phases is discussed in the following section.

Discussion about the electrochemical process and the charge storage mechanism. - The combined XRD, SEM and electrochemical 


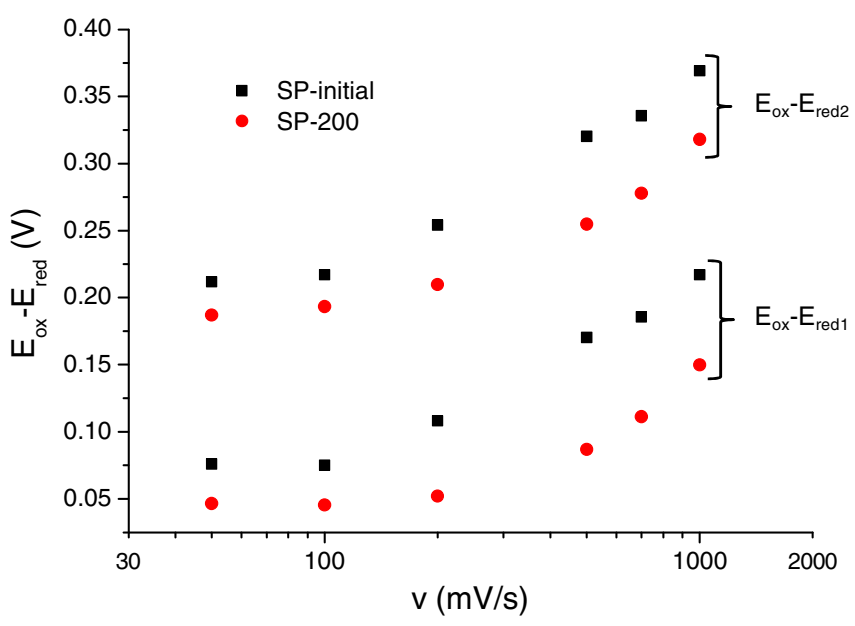

Figure 6. Variations of $E_{o x}-E_{r e d 1}$ and $E_{o x}-E_{r e d}$ potential differences as a function of scan rate for SP-initial and SP-200 cycled in microelectrode. $\mathrm{E}_{\mathrm{ox}}, \mathrm{E}_{\mathrm{red} 1}$ and $\mathrm{E}_{\mathrm{red} 2}$ correspond to potentials of the oxidation peak, the first reduction peak (at the highest potential) and the second reduction peak (at the lowest potential). The potential values are extracted from voltammograms presented in Fig. 5.

study has shown that i) the spinel structure is maintained within the electrode during the cycling between -0.4 and $0.75 \mathrm{~V}$ vs SHE (see Suppl. Figure 4), ii) platelets appear at the surface of the electrode, with a morphology characteristic of cobalt (oxi)hydroxide (see Fig. 7), iii) at $5 \mathrm{mV} / \mathrm{s}$ in a three electrode cell configuration (with classical macroelectrode), the initial spinel material undergoes oxidation reaction at high potential (peak overlapping with that of electrolyte oxidation), followed by a reduction at $0.47 \mathrm{~V}$ (see Fig. 3). The same experiment, performed with a microelectrode at $100 \mathrm{mV} / \mathrm{s}$, leads to one oxidation peak at $0.61 \mathrm{~V}$ and two reduction peaks at $0.41 \mathrm{~V}$ and $0.53 \mathrm{~V}$, which reflects the existence of three different cobalt oxidation states involved in the redox process.

Before any electrochemical reaction, the oxidation states $+2 /+3 /+4$ coexist for cobalt within the SP-initial material, with an average oxidation state of $2.80 .^{7-9}$ The following redox reactions are therefore supposed to be involved in the electrochemical cycling of SP-initial:

$$
\begin{aligned}
& \mathrm{Co}^{2+} \leftrightarrows \mathrm{Co}^{3+}+\mathrm{e}^{-} \\
& \mathrm{Co}^{3+} \leftrightarrows \mathrm{Co}^{4+}+\mathrm{e}^{-}
\end{aligned}
$$

In the case of the microelectrode experiment, the reduction peaks at 0.41 and $0.53 \mathrm{~V}$ can be reasonably attributed to the above two transitions, while the oxidation peak at $0.61 \mathrm{~V}$ may result from these superimposed reactions. From macroelectrode experiments, where only one oxidation and one reduction peak are observed, the two redox processes (Reactions 1 and 2) are assumed to overlap because of ohmic drop. This mechanism is in good accordance with those claimed by several authors for $\mathrm{Co}_{3} \mathrm{O}_{4}$-based electrodes, cycled in $\mathrm{KOH} .{ }^{21,24-26}$ The two redox couples observed by Cui et al. ${ }^{24}$ at $(0.54 / 0.33 \mathrm{~V})$ and $(0.60 / 0.45 \mathrm{~V})$, attributed to Reactions 1 and 2 respectively, exhibit potentials that are close to those obtained with the microelectrode $(0.61 / 0.43 \mathrm{~V})$ and $(0.61 / 0.53 \mathrm{~V})$. The formation of $\mathrm{Co}^{4+}$ ions is corroborated by Boggio et al., who shows that oxygen release at high potential happens only on the sites with +4 oxidation state. ${ }^{27}$

However, even if these redox transitions appear as a tantalizing clue, the electrochemical process involved is not totally elucidated. The oxidation of cobalt can indeed either be performed within the spinel structure, which requires deintercalation of cations such as protons or lithium from the tridimensional channel network, or coupled to structural changes. The major part of the studies reported in the literature assign the electrochemical signal of $\mathrm{Co}_{3} \mathrm{O}_{4}$ to the following
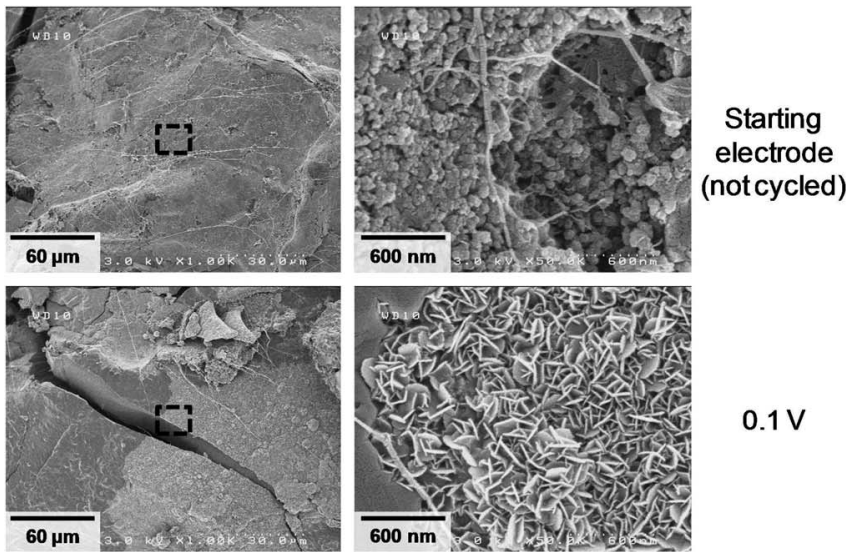

electrode

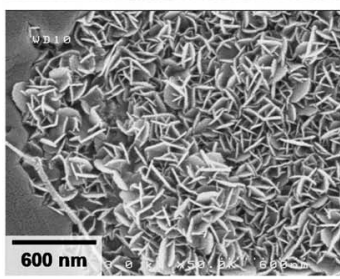

$0.1 \mathrm{~V}$
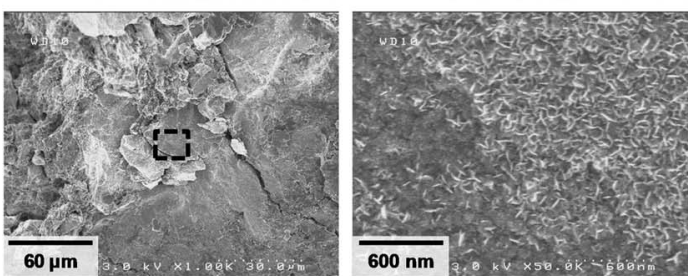

$0.6 \mathrm{~V}$
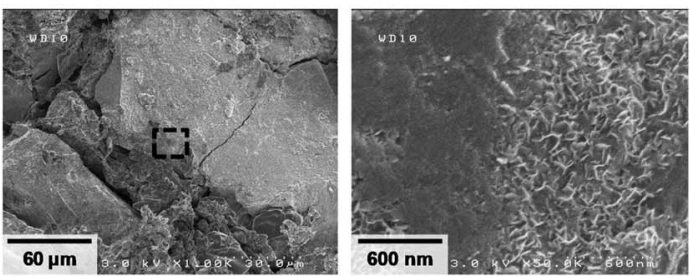

$0.7 \mathrm{~V}$

Figure 7. SEM pictures of electrodes containing "SP-initial" spinel cobalt oxide before cycling (starting electrode) and at fixed potentials during cycling $(0.1 \mathrm{~V}, 0.6 \mathrm{~V}$ and $0.7 \mathrm{~V})$. For each electrode, the picture on the right corresponds to a zoom of the central part indicated on the picture on the left. PTFE filaments can be observed in some pictures.

reactions, ${ }^{28-37}$ on the basis of the cobalt Pourbaix diagram: ${ }^{38}$

$$
\mathrm{Co}_{3} \mathrm{O}_{4}+\mathrm{OH}^{-}+\mathrm{H}_{2} \mathrm{O} \leftrightarrows 3 \mathrm{CoOOH}+\mathrm{e}^{-}
$$

$$
\mathrm{CoOOH}+\mathrm{OH}^{-} \leftrightarrows \mathrm{CoO}_{2}+\mathrm{H}_{2} \mathrm{O}+\mathrm{e}^{-}
$$

The formation of $\mathrm{CoO}_{2}$ is quite uncertain because that phase is usually rather unstable and can be obtained only by electrochemical deintercalation of $\mathrm{A}_{\mathrm{x}} \mathrm{CoO}_{2}$ type phases $(\mathrm{A}=\mathrm{H}, \mathrm{Li}, \mathrm{Na})$ at very high potentials. ${ }^{39,40} \mathrm{CoO}_{2}$ was brought to light by Mössbauer spectroscopy by Simmons et al., from cobalt hydroxides which were anodically treated at potentials higher than $0.85 \mathrm{~V}$ vs SHE. ${ }^{41}$ On the other hand, the presence of $\mathrm{CoOOH}$ would match with the platelet morphology observed at the surface of the electrode but only the $\beta$ (III) variety can be reasonably envisaged. The $\gamma$ variety (hydrated lamellar structure) is indeed excluded because it was shown by M. Butel to be irreversibly reduced to the $\beta$ (III) phase below $0.15 \mathrm{~V}^{42}$ As reported by this author, the study of the electrochemical cycling in $\mathrm{KOH}$ of the $\beta(\mathrm{II})-\mathrm{Co}(\mathrm{OH})_{2}$ and $\beta$ (III)-CoOOH phases in the $-0.3-0.7 \mathrm{~V}$ range involves a protondeficient $\beta$ (III)- $\mathrm{H}_{\mathrm{x}} \mathrm{CoO}_{2}$ phase, with a cobalt average oxidation state higher than 3 , which is denoted as $\beta^{\prime}(\mathrm{III})-\mathrm{CoOOH}$ :

$$
\beta(\mathrm{II})-\mathrm{Co}(\mathrm{OH})_{2} \mathrm{D} \underset{-0.01 \mathrm{~V}}{\stackrel{-0.06 \mathrm{~V}}{\leftrightarrows}} \beta(\mathrm{III})-\mathrm{CoOOH} \underset{0.24 \mathrm{~V}}{\stackrel{0.25 \mathrm{~V}}{\leftrightarrows}} \beta^{\prime}(\mathrm{III})-\mathrm{CoOOH}
$$

Starting from our spinel based electrode, the formation of the $\beta$ (III)$\mathrm{CoOOH}$ and $\beta^{\prime}(\mathrm{III})-\mathrm{CoOOH}$ phases appear therefore as possible, and could explain the platelets observed by SEM at the surface of our electrodes. Nevertheless, it should be kept in mind that, these two 
phases being not detected by XRD, their formation is necessarily restricted to a thin layer at the surface of the electrode. As a conclusion, the two processes, oxidation of cobalt within the spinel structure on one hand and formation of oxihydroxide phases on the other hand, are likely to coexist within our spinel based electrode.

As far as the nature of the charge storage is concerned, as shown as an example in Fig. 5, the shape of the cyclic voltametry curves shows intense redox peaks, which shows that the charge storage is essentially faradaic. However, the contribution of electrostatic charge storage cannot be totally neglected because the pore distribution, evaluated by a simple model on the basis of BET measurements, is centered on the $2-5 \mathrm{~nm}$ narrow range. It is possible to evaluate roughly the thickness at the surface of the material particles that may be affected by the redox processes previously described. For this purpose, in a first step, it is necessary to evaluate the percentage of cobalt atoms covering the surface of our $\mathrm{Co}_{3} \mathrm{O}_{4}$-type nanoparticles. According to a simple model where we consider a spherical particle with oxygen atoms arranged with a fcc packing, the percentage of oxygen atoms at the surface of a particle can be evaluated as $400 \mathrm{r}_{\text {oxygen }} / \mathrm{r}_{\text {particle }}$. The detailed calculation is presented as supplementary information. $r_{\text {oxygen }}$ and $r_{\text {particle }}$ correspond to the radius of oxygen $(0.14 \mathrm{~nm})$ and of the particle $(5 \mathrm{~nm})$, which leads to $11 \%$ of oxygen at the very surface. Using the stoichiometric formula of our SP-initial material $\left(\mathrm{H}_{1.34} \mathrm{Li}_{0.14} \mathrm{Co}^{\mathrm{II}}{ }_{0.61}\left[\mathrm{Co}^{\mathrm{III}}{ }_{1.58} \mathrm{Co}^{\mathrm{IV}}{ }_{0.14}\right] \mathrm{O}_{4} \bullet 0.32 \mathrm{H}_{2} \mathrm{O}\right)$, the $\mathrm{Co} / \mathrm{O}$ ratio is equal to 0.58 , which leads to conclude that around $6 \%$ of the Co atoms are located in a shell at the very surface of the particles. On the other hand, if all cobalt ions present in the material particles are supposed to be converted to +4 during the oxidation process, the theoretical capacity of our SP-initial material can be calculated with the formula $\mathrm{Q}_{\mathrm{th}}(\mathrm{mA} \cdot \mathrm{h} / \mathrm{g})=\frac{(0.61 \times 2+1.58 \times 1) F}{3.6 \mathrm{M}}$, where F corresponds to the Faraday constant (96500) and $\mathrm{M}$ to the molecular weight of the material $(\mathrm{M}=209 \mathrm{~g} / \mathrm{mol})$. The value obtained is $\mathrm{Q}_{\mathrm{th}}=358 \mathrm{~mA} . \mathrm{h} / \mathrm{g}$. The capacity we obtained experimentally $(73 \mathrm{~mA} . \mathrm{h} / \mathrm{g})$ shows that about $20 \%$ of the theoretical capacity is extracted. $6 \%$ of cobalt being located at the surface of the nanoparticles, the $20 \%$ of the cobalt ions involved in the electrochemical process represent roughly 3-4 cobalt atomic layers, i.e. a thickness lower than $10 \AA$ at the surface of the particles. The very small thickness that is affected at the particle surface by the electrochemical cycling allows to explain that no structural change can be detected by XRD during cycling.

Electrochemical stability of the electrode based on the material SP-initial.-The SP-initial sample exhibits an excellent chemical stability since, after one year soaking in $8 \mathrm{M}-\mathrm{KOH}$, no blue color of the solution, characteristic of $\mathrm{Co}(\mathrm{OH})_{4}{ }^{2-}$ complexes resulting from cobalt dissolution in alkaline medium, could indeed be detected. ${ }^{43,44}$ In addition, the XRD analysis of the electrode did not reveal any structural change of the $\mathrm{Co}_{3} \mathrm{O}_{4}$ type phase and appearance of an additional phase.

The electrochemical stability was also investigated. As illustrated in Fig. 8, the electrochemical ageing is quite satisfying, since $91 \%$ of the initial cathodic capacity is maintained after 500 cycles, and $70 \%$ after 3500 cycles. The coulombic efficiency is kept higher than $92 \%$ all along the cycling, in an open cell configuration. Nevertheless, it should be noticed that the coulombic efficiency will become a crucial parameter in a complete closed supercapacitor cell, where values higher than $97 \%$ are required, to avoid any separator drying, or excessive electrolyte consumption, which would result in overpressure problems due to oxygen release. Normally, the electrochemical stability should be strongly improved in an asymmetric $\mathrm{Co}_{3} \mathrm{O}_{4} / \mathrm{C}$ supercapacitor configuration, because the carbon electrode will support one part of charge/discharge and exhibits an excellent stability (more than 99\%).

As a conclusion, the electrochemical behavior of our nanometric $\mathrm{Co}_{3} \mathrm{O}_{4}$ type phases are quite encouraging, with capacities higher than those obtained for numerous oxides, such as $\mathrm{MnO}_{2}, 3,4,46$ $\mathrm{Fe}_{3} \mathrm{O}_{4},{ }^{7} \mathrm{NiO}^{8,47}$ or $\mathrm{V}_{2} \mathrm{O}_{5} \cdot{ }^{6,7}$ The capacities are in the same range as many cobalt oxides, hydroxides and oxihydroxides reported in

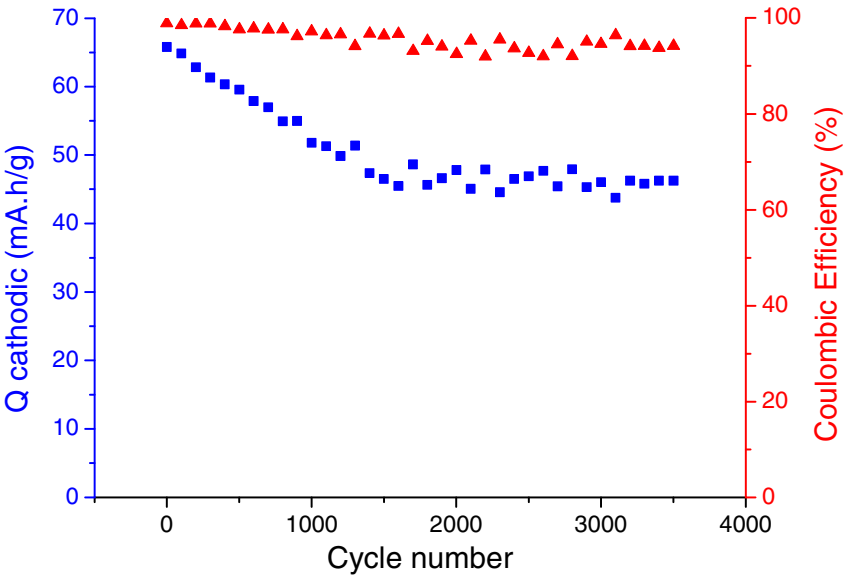

Figure 8. Variations of cathodic capacity and coulombic efficiency of an electrode containing "SP-initial" spinel cobalt oxide (and 5\% carbon black added) over 3500 cycles. The values were extracted from cyclic voltammetry measurements performed at $5 \mathrm{mV} / \mathrm{s}$ in $5 \mathrm{M}-\mathrm{KOH}$ in the $-0.4-0.75 \mathrm{~V}$ potential range.

literature for similar cycling configurations and active material amounts. ${ }^{21,24-26,32,35,37}$ Capacities reported for cobalt oxide/hydroxide thin films are indeed as expected higher, ${ }^{22,31,33}$ due to the weak amounts of cobalt oxide (lower than $1 \mathrm{mg} / \mathrm{cm}^{2}$ ), and the possible contribution of current collector in some cases.

\section{Conclusions}

Spinel type materials with structural defects and typical formula such as $\mathrm{H}_{1.34} \mathrm{Li}_{0.14} \mathrm{Co}^{\mathrm{II}}{ }_{0.61}\left[\mathrm{Co}^{\mathrm{III}}{ }_{1.58} \mathrm{Co}^{\mathrm{IV}}{ }_{0.14}\right] \mathrm{O}_{4} \bullet 0.32 \mathrm{H}_{2} \mathrm{O}$ were prepared through a precipitation method. The electronic conductivity of such compounds is quite interesting for supercapacitor application and can be increased from $3 \cdot 10^{-4} \mathrm{~S} \cdot \mathrm{cm}^{-1}$ up to $10^{-1} \mathrm{~S} \cdot \mathrm{cm}^{-1}$ by a simple heat-treatment at $200^{\circ} \mathrm{C}$. Thanks to a good coulombic efficiency $(>92 \%)$, such kind of spinel cobalt oxide exhibits a very good stability upon cycling (up to 3500 cycles with less than $30 \%$ loss), which makes them very good candidates for asymmetric supercapacitors. Despite the charge storage mechanism is still being under investigation, our results show that at least two redox processes are involved, with both the spinel and oxihydroxide/hydroxide cobalt species. Besides, it turns out that only a thin material surface layer seems to contribute to the charge storage, leading to a gravimetric capacity of around $70 \mathrm{~mA} \cdot \mathrm{h} \cdot \mathrm{g}^{-1}$, whereas the theoretical capacity is $220 \mathrm{~mA} \cdot \mathrm{h} \cdot \mathrm{g}^{-1}$. Further work is now focused on improving the percolation and the morphology of the particles to take benefit of the whole capacity of such promising materials.

\section{Acknowledgments}

This work was supported by French National Research Agency (ANR-08-STOCK-E-09-01). The authors thank P. Dagault, C. Denage and S. Goma for their technical support.

\section{References}

1. J. P. Zheng, P. J. Cygan, and T. R. Jow, J. Electrochem. Soc., 142, 2699 (1995).

2. C. Lin, J. A. Ritter, and B. N. Popov, J. Electrochem. Soc., 147, 4097 (1998).

3. H. Y. Lee and J. B. Goodenough, J. Solid State Chem., 144, 220 (1999).

4. T. Brousse, M. Toupin, R. Dugas, L. Athouël, O. Crosnier, and D. Bélanger, J. Electrochem. Soc., 153, A2171 (2006).

5. C. Xu, F. Kang, B. Li, and H. Du, J. Mater. Res., 25, 1421 (2010).

6. H. Y. Lee and J. B. Goodenough, J. Solid State Chem., 148, 81 (1999).

7. T. Cottineau, M. Toupin, T. Delahaye, T. Brousse, and D. Bélanger, Appl. Phys. A, 82, 599 (2006).

8. K. R. Prasad and N. Miura, Appl. Phys. Lett., 85, 4199 (2004).

9. G. A. Snook, P. Kao, and A. S. Best, J. Power Sources, 196, 1 (2011).

10. Scopus, Research of the papers involving " $\mathrm{MnO}_{2}$ " and "supercapacitor"-2012-2015 
11. G. Wang, B. Zhang, Z. Yu, and M. Qu, Solid State Ionics, 176, 1169 (2005).

12. Q. Cheng, J. Tang, J. Ma, H. Zhang et al., Carbon, 49, 2917 (2011).

13. S. Lee, J. Kim, S. Chen, P. Hammond et al., ACS Nano, 4, 3889 (2010).

14. V. Subramanian, H. Zhu, and B. Wei, Electrochemistry Communications, 8, 827 (2006).

15. K. M. Shaju, L. Guerlou-Demourgues, G. Godillot, F. Weill, and C. Delmas, $J$. Electrochem. Soc., 159(12), A1934 (2012).

16. G. Godillot, Hua Huo, M. Ménétrier, L. Bourgeois, L. Guerlou-Demourgues, and C. Delmas, J. Phys. Chem. C, 116, 26598 (2012)

17. G. Godillot, L. Guerlou-Demourgues, L. Croguennec, K. M. Shaju, and C. Delmas, J. Phys. Chem. C, 117, 9065 (2013)

18. G. Godillot, L. Guerlou-Demourgues, P.-L. Taberna, P. Simon, and C. Delmas, Elec trochemical and Solid-State Letters, 14(10), A139 (2011)

19. F. Grillo, M. M. Natile, and A. Glisenti, Appl. Catal. B, 48, 267 (2004)

20. Y.-Z. Wang, Y.-X. Zhao, C.-G. Gao, and D.-S. Liu, Catal. Lett., 116, 136 (2007)

21. L.-B. Kong, J.-W. Lang, M. Liu, Y.-C. Luo, and L. Kang, J. Power Sources, 194 1194 (2009).

22. W.-J. Zhou, M.-W. Xu, D.-D. Zhao, C.-L. Xu, and H.-L. Li, Microporous Mesoporous Mater., 117, 55 (2009)

23. F. Tronel, L. Guerlou-Demourgues, L. Goubault, P. Bernard, and C. Delmas, J. Power Sources, 179, 837 (2008).

24. L. Cui, J. Li, and X.-G. Zhang, J. Appl. Electrochem., 39, 1871 (2009).

25. L. Wang, X. Liu, X. Wang, X. Yang, and L. Lu, Curr. Appl. Phys., 10, 1422 (2010)

26. C. Xu, J. Sun, and L. Gao, CrystEngComm., 13, 1586 (2011).

27. R. Boggio, A. Carugati, and S. Trasatti, J. Appl. Electrochem., 17, 828 (1987).

28. Y. Gao, S. Chen, D. Cao, G. Wang, and J. Yin, J. Power Sources, 195, 1757 (2010).

29. E. Hosono, S. Fujihara, I. Honma, M. Ichihara, and H. Zhou, J. Power Sources, 158 779 (2006).
30. J.-J. Deng, J.-C. Deng, Z.-L. Liu, H.-R. Deng, and B. Liu, J. Solid State Electrochem., 13, 1387 (2009).

31. X. Qing, S. Liu, K. Huang, K. Lv, Y. Yang, Z. Lu, D. Fang, and X. Liang, Electrochim. Acta, 56, 4985 (2011).

32. D. Wang, Q. Wang, and T. Wang, Inorg. Chem., 50, 6482 (2011)

33. C. Yuan, L. Yang, L. Hou, L. Shen, F. Zhang, D. Li, and X. Zhang, J. Mater. Chem., 21, 18183 (2011).

34. M. Aghazadeh, J. Appl. Electrochem., 42, 89 (2012).

35. B. Duan and Q. Cao, Electrochim. Acta, 64, 154 (2012).

36. X. Wang, A. Sumboja, E. Khoo, C. Yan, and P. S. Lee, J. Phys. Chem. C, 116, 4930 (2012).

37. X.-h. Xia, J.-p. Tu, Y.-q. Zhang, Y.-j. Mai, X.-1. Wang, C.-d. Gu, and X.-b Zhao, RSC Adv., 2, (2012) 1835

38. M. Pourbaix et al., Atlas d'équilibres électrochimiques, p.325, Gauthier-Villars et Cie, Paris (1963).

39. G. G. Amatucci, J. M. Tarascon, and L. C. Klein, J. Electrochem. Soc., 143, 1114 (1996).

40. T. Motohashi, Y. Katsumata, T. Ono, R. Kanno, M. Karppinen, and H. Yamauchi, Chem. Mater, 19, 5063 (2007).

41. G. W. Simmons, A. Vertes, M. L. Varsanyi, and H. Leidheiser Jr., J. Electrochem. Soc., 126, 187 (1979).

42. M. Butel, PhD thesis, University of Bordeaux (1998).

43. V. Pralong, A. Delahaye-Vidal, B. Beaudoin, J. B. Leriche, J. Scoyer, and J.-M. Tarascon, J. Electrochem. Soc., 147, 2096 (2000).

44. F. Tronel, L. Guerlou-Demourgues, L. Goubault, P. Bernard, and C. Delmas, J. Power Sources, 179, 837 (2008).

45. A. Pandolfo and A. Hollenkamp, J. Power Sources, 157, 11 (2006).

46. C. Xu, F. Kang, B. Li, and H. Du, J. Mater. Res., 25, 1421 (2010).

47. K.-C. Liu and M. A. Anderson, J. Electrochem. Soc., 143, 124 (1996). 